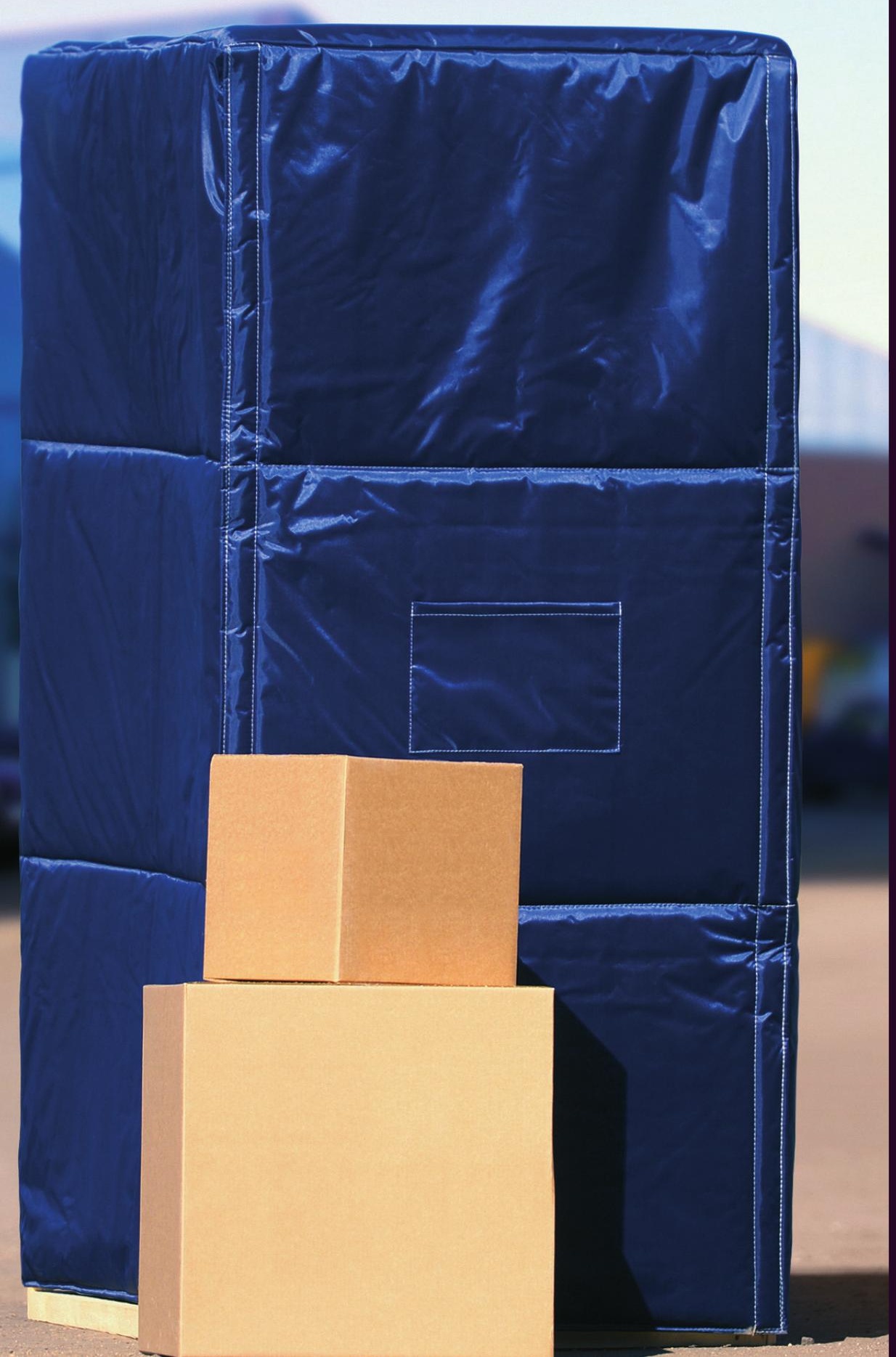

Термочехлы для транспортировки продуктов питания 

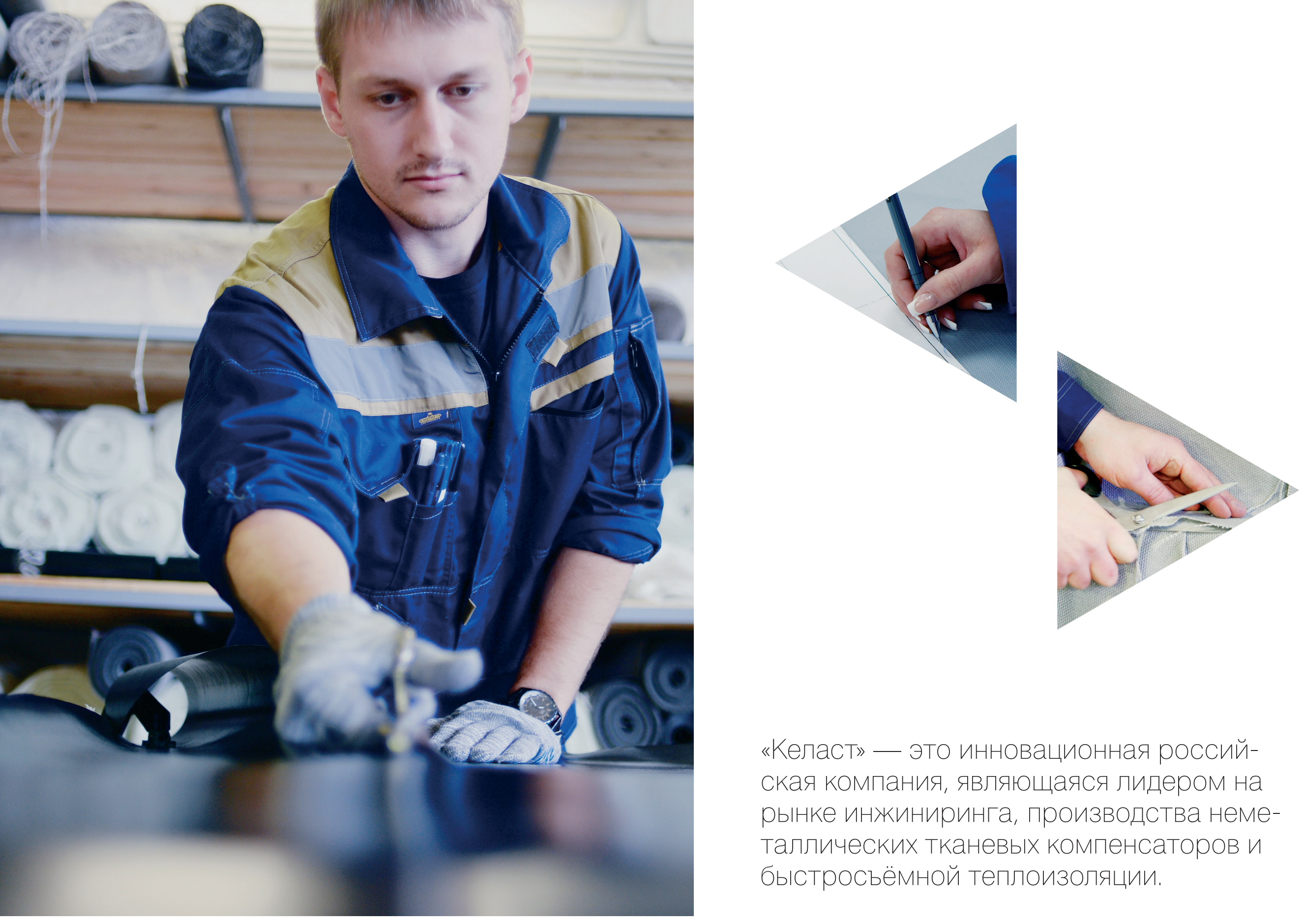

«Келаст» — это инновационная российская компания, являющаяся лидером на рынке инжиниринга, производства неметаллических тканевых компенсаторов и быстросъёмной теплоизоляции. 
Термочехлы для европаллет или рольбоксов предназначены для температурной защиты транспортируемых продуктов. Задача термочехлов состоит в сохранении собственной температуры груза, независимо от температуры наружного воздуха. Термочехлы позволяют совмещать перевозку продуктов с различными температурными режимами хранения:

Если раньше под каждый температурный режим необходим был отдельный фургон / ресриижератор, то с использованием наших термочехлов возможна совместная транспортировка заморозки $\left(-18^{\circ} \mathrm{C}\right)$, ох-

лаждённого мяса и рыбы $\left(+2^{\circ} \mathrm{C}\right)$, фрруктов и овощей $\left(+6^{\circ} \mathrm{C}\right)$, бананов и экзотических орруктов $\left(+15^{\circ} \mathrm{C}\right)$, а также сухих продуктов $\left(+20^{\circ} \mathrm{C}\right)$. Это позволяет свести к минимуму затраты на перевозку.
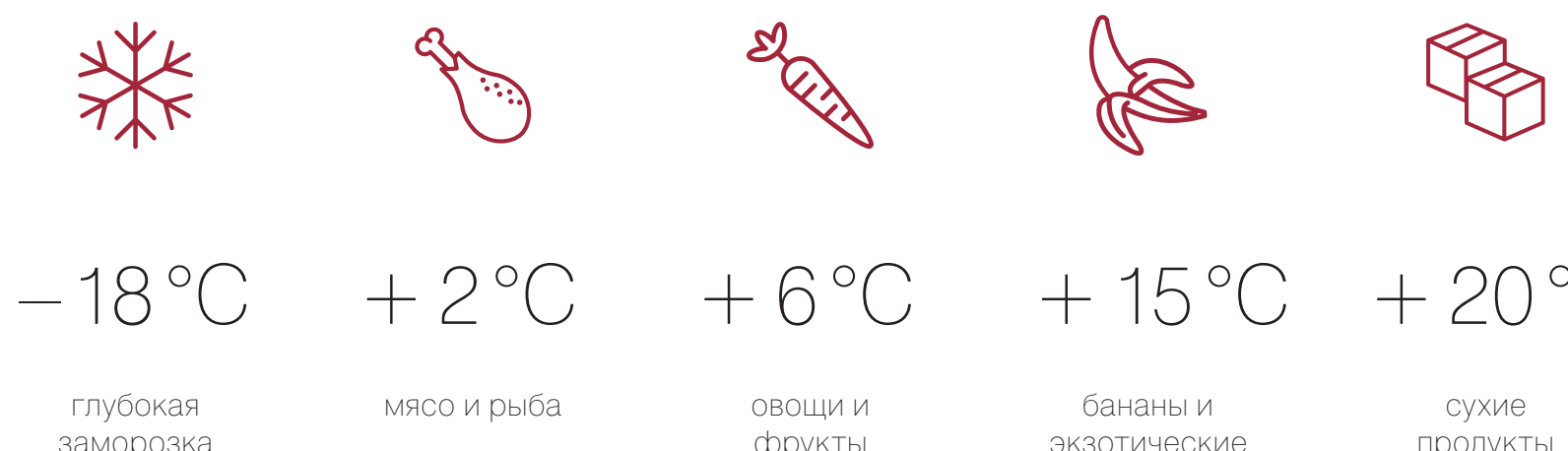

заморозка

оррукты

әкзотически

сррукты

сухие

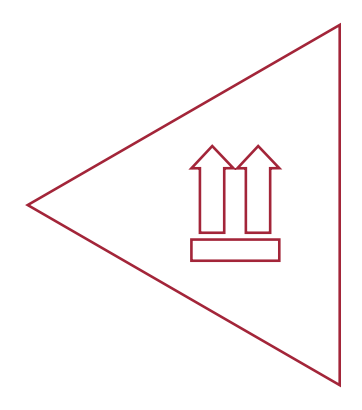


Совместно с ведущими ритейлерами наши специалисты провели испытания для различных условий эксплуатации охлахкённых и замороженных продуктов, в результате чего были оптимально подобраны материалы с низким коэфофициентом теплопроводности изоляционного наполнителя.

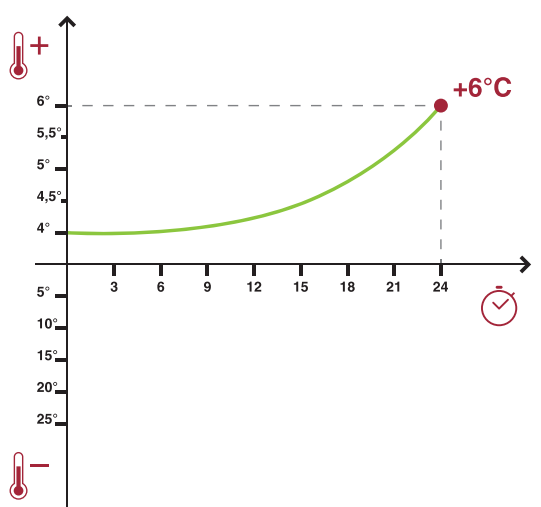

Внутри - охлаждённое мясо Снаружи - тепло $\left(+20^{\circ} \mathrm{C}\right)$

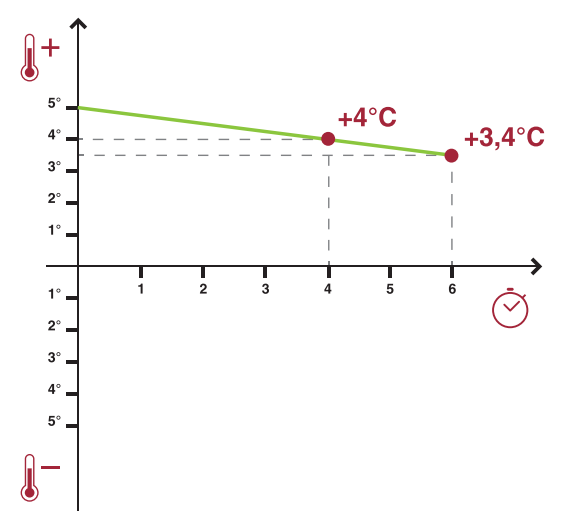

Внутри - охлаждённое мясо Снаружи - холодно $\left(-20^{\circ} \mathrm{C}\right)$

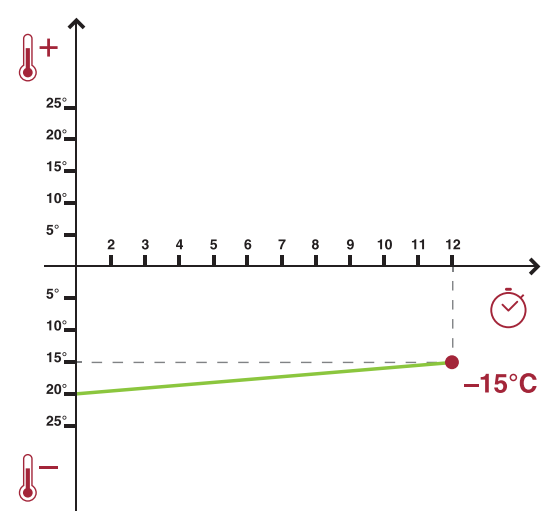

Внутри - замороженная рыба Снаружи - тепло $\left(+20^{\circ} \mathrm{C}\right)$

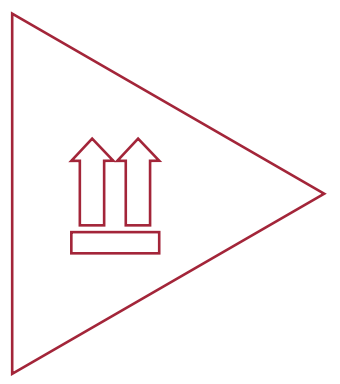

Граффики сохранения температуры внутри термочехла Kelast ${ }^{\circledR}$ : 

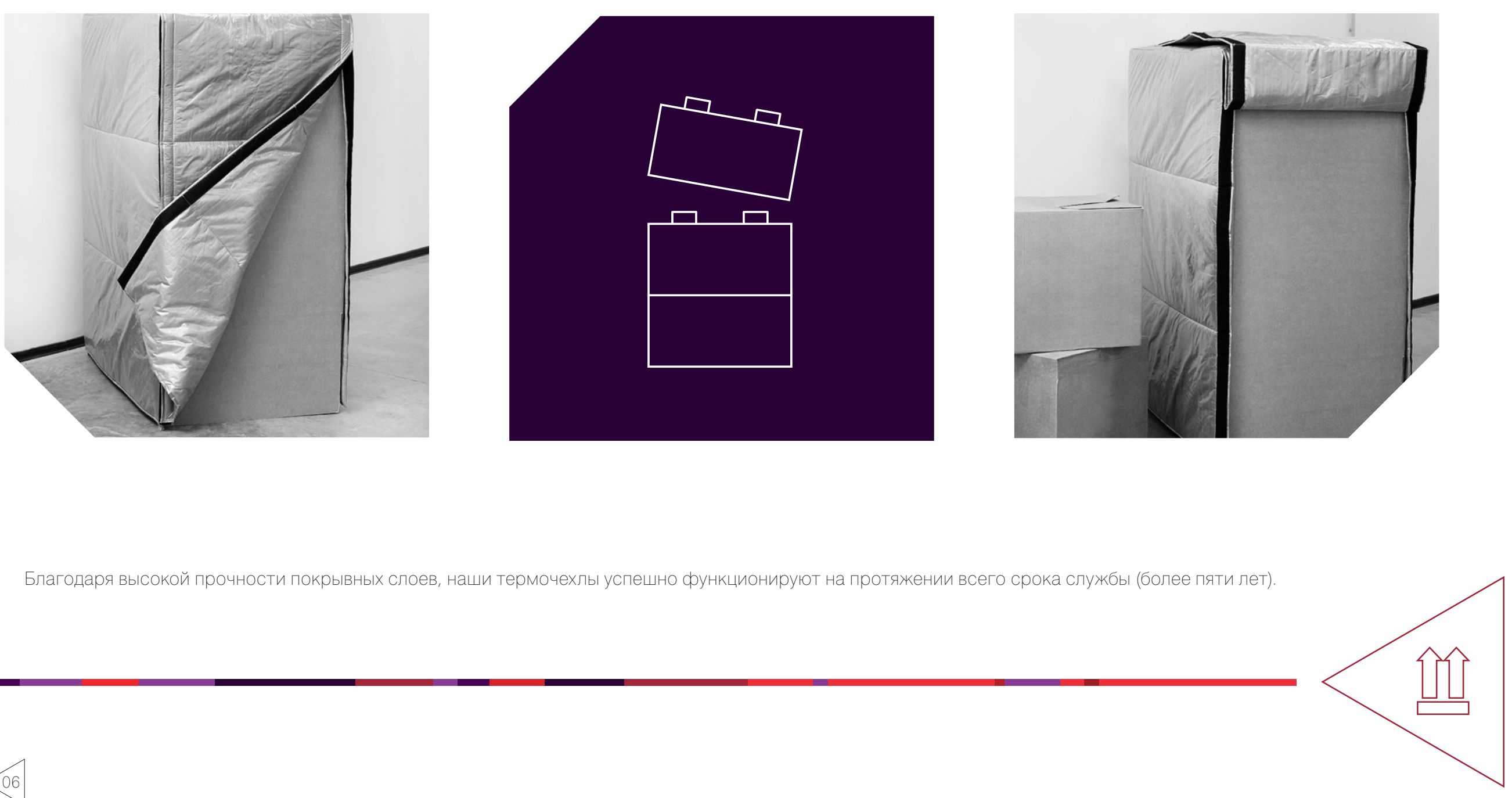
Отличительной особенностью термочехлов Kelast ${ }^{\oplus}$ является использование

современных материалов с заданными техническими свойствами.

Требования, предьявляемые к термочехлам для перевозки продуктов питания:

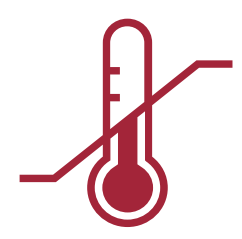

B постоянство теплопроводности при изменении температуры и влажности

механическая прочность материалов,

прочность на разрыв, износостойкость

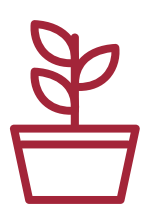

экологическая чистота

и отсутствие аллергенов

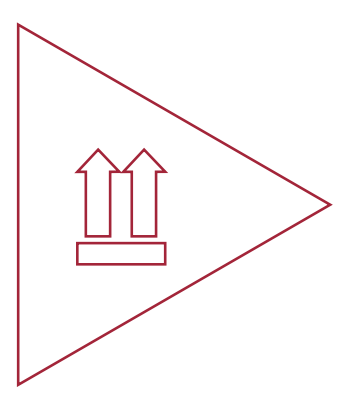

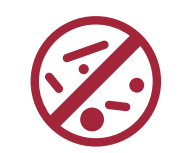

поверхность и наполнение термочехла препятствуют размножению бактерий и микроорганизмов 


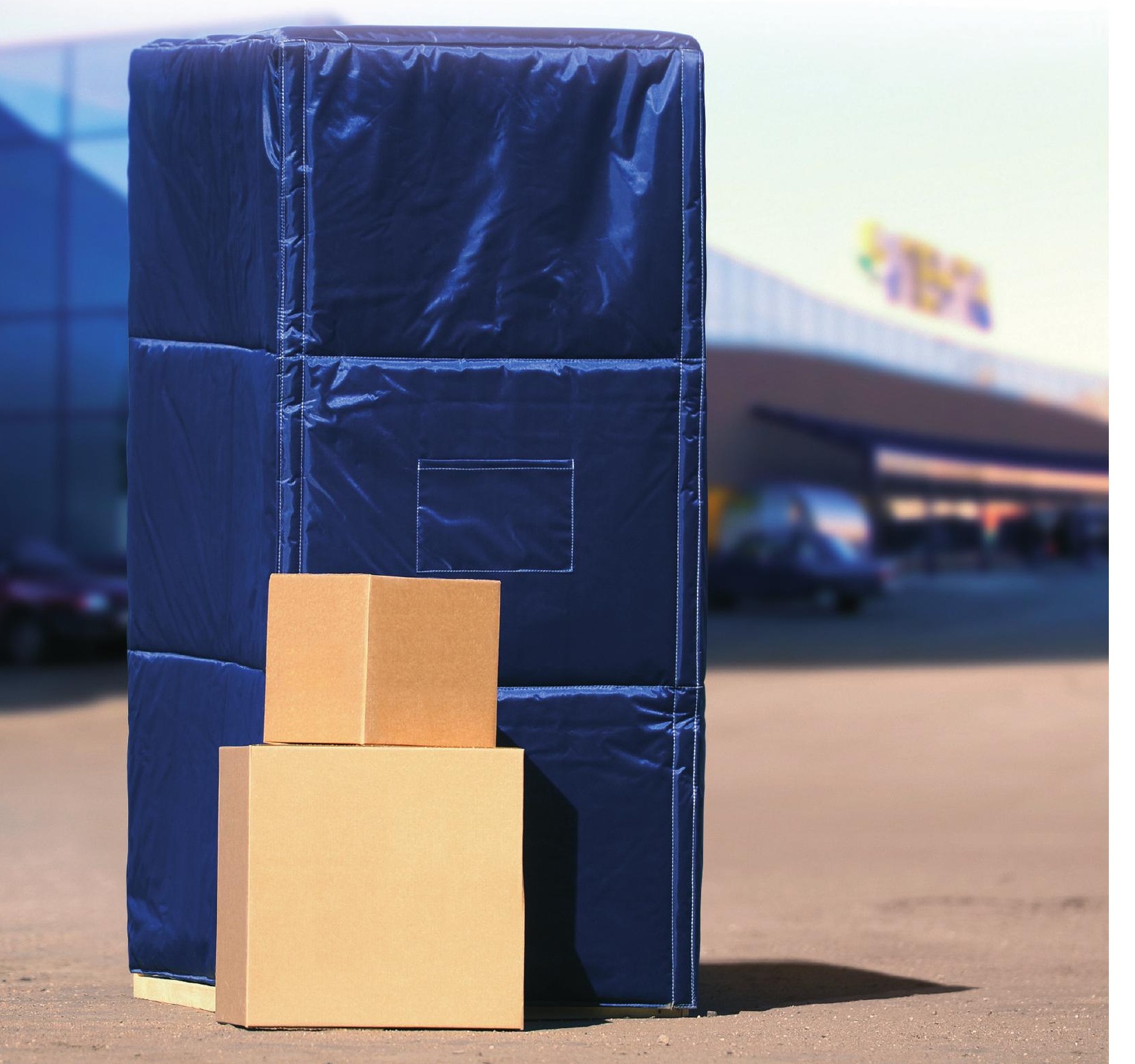

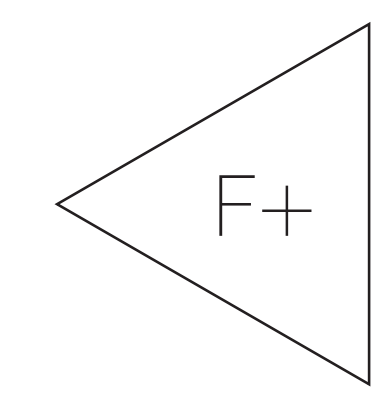

способны выдерживать экстремальную механи-

$$
\text { ческую нагрузку }
$$

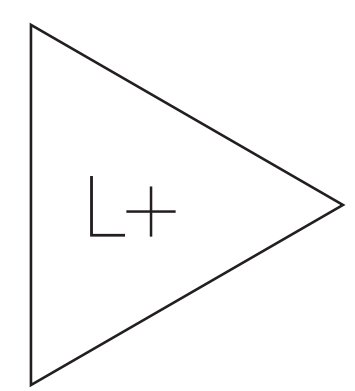

подходят для транспортировки грузов на дальние расстояния 


\section{СПЕЦИАЛЬНЫЕ МАТЕРИАЛЫ}

KELAST ${ }^{\oplus}$
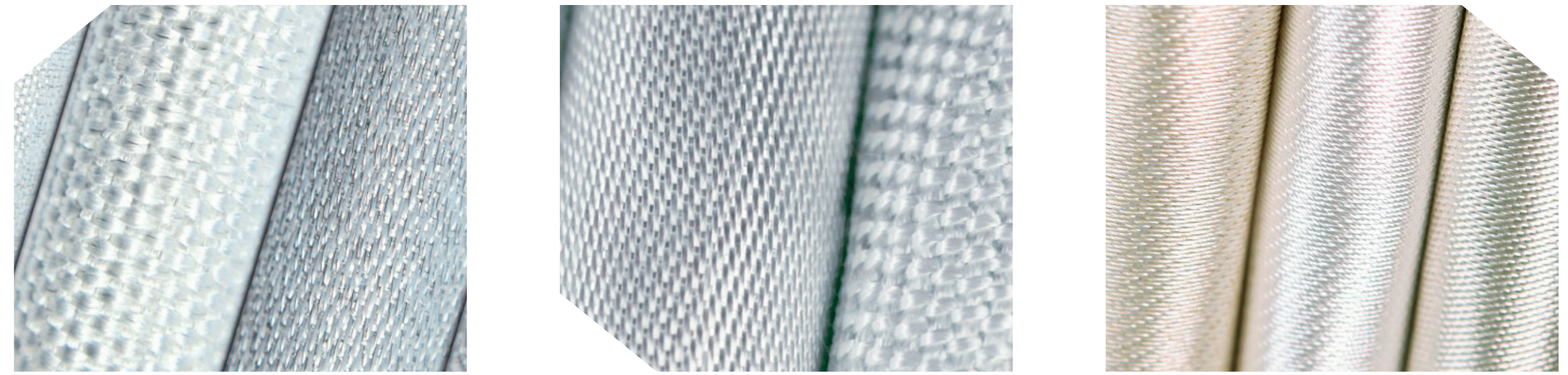

Термоизоляционный слой «ЭЛАТЕКС BK», применяемый в чехлах серии SZ и FZ, специально разработан для термочехлов и отвечает строгим эКсплуатационным требованиям отрасли. Материал на основе улучшенных полиэфирных волокон имеет плотное переплетение, обеспечивая отсутствие остаточной десормации на сжатие Это сохраняет теплосизические свойства материала на протяжении всего срока эксппуатации.

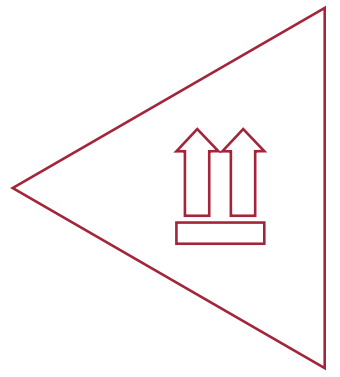


$\mathbb{1}_{\text {k }}$ kelast

ООО «Келаст»

Индустриальная, 18

Панковка, Великий Новгород

Россия, 173526

+7 (8162) 64-53-34

info@kelast.ru

www.kelast.ru 